\title{
Atorrantes. Categorías marxistas para una nueva interpretación de una figura popular a fines del siglo XIX en Buenos Aires (El Obrero, 1890-1892)
}

\section{Atorrantes. Marxist categories for a new interpretation of a popular figure at the end of the 19th century in Buenos Aires (El Obrero, 1890-1892)}

\author{
Sabina Dimarco*
}

\begin{abstract}
Resumen: El uso del término atorrante comenzó a extenderse entre los porteños a partir de 1880 y una década más tarde ya se encontraba consolidado en el vocabulario urbano: en el habla popular, la prensa y la narrativa policial pero también en las obras de importantes referentes intelectuales de la época. La extendida creencia en la Argentina como un país de oportunidades laborales llevaba a una interpretación de las situaciones de ausencia de trabajo rentado como marginalidad voluntaria. La figura del atorrante, que se asociaba fundamentalmente a hombres jóvenes, sanos y extranjeros, es decir, al potencial trabajador, sintetizaba esa idea. En ese mismo contexto un sector del socialismo de perspectiva marxista, nucleados en torno al periódico El Obrero, buscó imponer una interpretación diferente del atorrante. El presente artículo se interroga por el modo en que desde esa publicación se pensó el lugar que ocupaban los "sin trabajo", en particular aquellos identificados como atorrantes, en la estructura social argentina y el rol que podían jugar en una clase obrera en formación. Indaga en particular en el modo en que se movilizaron las categorías marxistas en vistas a resignificar a esa estigmatizada figura y convertirla en parte de un sector obrero al que aspiraban a representar. Esto nos permite reflexionar acerca de algunas de las formas, menos estudiadas, que adoptó la puja por la constitución de una identidad obrera en esta etapa embrionaria. En particular, la disputa por la definición de los problemas obreros, de una parte, y por la demarcación de los límites mismo de la categoría de "trabajador" (y su reverso) de otra.
\end{abstract}

Palabras clave: socialismo, atorrantes, "sin trabajo", marxismo, categorías sociales

\footnotetext{
* Argentina, Doctora en Ciencias Sociales por la UBA, Magister por la École des Hautes Études en Sciences Sociales (EHESS) de Paris, Investigadora del Consejo Nacional de Investigaciones Científicas y Técnicas (CONICET/ICI-UNGS), docente de la Universidad Nacional de General Sarmiento, sabinadimarco@hotmail.com
} 


\begin{abstract}
The use of the term atorrante began to be spread among locals after 1880 and, a decade later, was already consolidated in the urban vocabulary: in popular language, the press and police narrative but also in the works of important intellectual referents. Because of the wide belief that Argentina was a country of job opportunities, the situations of absence of paid work used to be interpreted as voluntary marginality. The atorrante, who was associated with a young man, healthy and foreign, that is, the potential worker, synthesized that idea. In that same context, a sector of socialist with a marxist perspective, centered around the newspaper El Obrero, sought to impose a different interpretation of the atorrante. This article analyzes the way in wich the place occupied by the "without work" was considered from that publication -particularly those identified as atorrantes- in the Argentine social structure and the role they could play in a working class formation. The aim of the article is to analyse the use of marxist categories in order of resignify that stigmatized figure and include it in the worker's sector to which they aspired to represent. This allows us to reflect on some of the less studied forms adopted by the fight for the constitution of a worker identity in this embryonic stage. In particular, the dispute over the definition of workers' problems and the demarcation of the limits of the category of "worker" (and its reverse side).
\end{abstract}

Keywords: socialism, atorrantes, "out of work", Marxism, social categories

Recibido: 31 mayo 2018 Aceptado: 4 julio 2018

\title{
Introducción
}

(Hay algunas) voces que han echado raíces en nuestro suelo, sin que se sepa de dónde vino la semilla primitiva. Una de ellas es atorrante. (...) Después de haber vivido más de un cuarto de siglo la oí por primera vez en mi tierra, allá por el año 1884, de regreso de Europa, donde había pasado algunos años. Y no es que hubiera vivido en mi país entre académicos y prosistas, pues hasta cronista de policía substituto había sido en la vieja Tribuna. Pregunté qué significaba atorrante y de dónde venía. Se me hizo la descripción de gueux, del vagabundo, del chemineux, y se me dijo entonces (no hay lomo como el de la etimología para soportar carga) que el vocablo tomaba origen en el hecho de que los individuos del noble gremio así denominado dormían en los caños enormes que obstruían entonces nuestras calles, llamados de tormenta. De ahí atorrante. Miguel Cané, Prosa Ligera, 1903.

El uso del término atorrante comenzó a extenderse entre los porteños a partir de $1880^{1}$ y una década más tarde ya se encontraba consolidado en el vocabulario urbano. A

1José Gobello y Jorge Alberto Bossio, El Atorrante, Buenos Aires, Ediciones del Candil, 1968; José Gobello, Lunfardía. Acotaciones al lenguaje porteño, Buenos Aires, Dunken, 2001. Gobello atribuye su etiología a dos 
partir de las primeras décadas del siglo XX fue perdiendo fuerza, pero nunca desapareció del todo llegando incluso hasta nuestros días. Desde ese entonces y hasta hoy, el término se utiliza para designar a la vagancia, la holgazanería o la picardía y astucia para aprovecharse el trabajo ajeno, ${ }^{2}$ aunque con el tiempo fue adquiriendo un sentido algo más burlón que en sus comienzos. Como sugieren los párrafos citados en el epígrafe, en su origen hacía referencia fundamentalmente a personas de origen extranjero, y generalmente se lo usaba para señalar y condenar a personas que llevaban una conducta contraria a la cultura del trabajo que se estaba intentado inculcar y que, según esperaban las elites dirigentes, debía llegar justamente con esa población inmigrante. ${ }^{3}$ Así, cuando se hablaba de los atorrantes, ya fuera que se lo hiciese desde una visión idealizada ${ }^{4} \mathrm{O}$ condenatoria, se buscaba resaltar (positiva o negativamente en cada caso) el rechazo a la disciplina del trabajo como forma de ganarse el sustento.

En las últimas décadas del siglo XIX no sólo el término era utilizado en el habla popular, la prensa y la narrativa policial sino también en las obras de importantes referentes intelectuales de la época. El reconocido médico higienista José M. Ramos Mejía definía a los atorrantes como "alcoholistas (sic), vagos y haraganes", y Miguel Cané como "gueux", "vagabundo", "chemineux". En todos los casos se los describía como extranjeros: "una planta exótica" o "producto importado" según Antonio Dellepiane, mientras que Emile Daireaux hablaba de "desechos de una inmigración mal dirigida". Y puesto que predominaba la idea de que en la Argentina agroexportadora sobraban las oportunidades de trabajo para todo aquel dispuesto a esforzarse, se concluía de manera generalizada que -para decirlo con los términos de E. Daireaux- "... en un país donde el trabajo es fácil (...) no existen más pobres que los de profesión". 5 Dicho de otro modo, la creencia en que el país ofrecía posibilidades de empleo para quien quisiera trabajar conducía a que toda situación de ausencia de ocupación rentada comprobable fuese interpretada como un problema de marginalidad voluntaria por parte de personas que optaban por vivir sin trabajar. La figura del atorrante, que se asociaba fundamentalmente a hombres jóvenes y sanos, es decir, al potencial trabajador, sintetizaba esa idea.

Pero la década de 1890, cuando más se afirma la utilización del término, estuvo atravesada por dos graves crisis económicas con agudas consecuencias en las oportunidades laborales para la población. En ese contexto los socialistas de perspectiva marxista nucleados en torno al periódico El Obrero, que comenzó a editarse justamente en esos años de crisis, buscaron brindar una peculiar interpretación tanto de los "atorrantes"

explicaciones: la primera lo vincula al nombre de la compañía que construía los caños en los que solían refugiarse ("A. Torrant") y la segunda al verbo "atorrar" (dormir) que ya existía en el vocabulario del lunfardo. 2La Real Academia Española brinda tres definiciones: 1. Vago u holgazán; 2. Desfachatado, desvergonzado; 3. Vagabundo sin domicilio fijo. Aclara que se trata de un adjetivo despectivo que proviene de Argentina y Uruguay (y en el tercer caso también de Costa Rica y Rep. Dominicana).

3 Maristella Svampa, ¿Civilización o barbarie? El gran dilema de los argentinos, Buenos Aires, Ed. El cielo por asalto, 1994.

4 Lucas Rubinich (2008) habla de una mirada "romántico vitalista" para dar cuenta de esta perspectiva idealizada o celebratoria de cierto tipo de transhumante. Lucas Rubinich, "Van los linyeras... Construcción y circulación de una noción positiva del individualismo romántico vitalista durante la primera mitad del siglo XX argentino", Apuntes de Investigación, No 13, 2008, 53-99.

5 Emile Daireaux, La vie et les moeurs a La Plata, Paris, Hachette, 1888, p.170. 
como de la crisis de 1890 y, en particular, de la articulación entre ambos fenómenos. A través de diversas notas publicadas en ese espacio este grupo de socialistas, con Germán Avé Llalemant a la cabeza, disputaron esas ideas tan generalizadas en su tiempo y fueron forjando, a través de esa figura social, una interpretación diferente - pero a su vez acorde a lo que estaba sucediendo en el continente europeo- de la falta de trabajo. ${ }^{6}$

En el marco de un proceso incipiente de organización de la clase obrera en el país, en el que los socialistas nucleados en torno a El Obrero creían e intervenían con convencimiento, el presente artículo se interroga por el modo en que desde este sector del socialismo se pensaba el lugar que ocupaban los "sin trabajo" en la estructura social argentina y el rol que podían jugar en esa clase obrera en formación. Nos interesa en particular indagar en el modo en que en ese proceso movilizaron las categorías marxistas, a las que suscribían los redactores de El Obrero, para resignificar a la estigmatizada figura del atorrante.Partimos de la hipótesis de que la recepción de esas ideas, como sucede en todo proceso de circulación de este tipo, se encuentra atravesada por las especificidades del campo receptor ${ }^{7}$ y que este grupo de socialistas marxistas se valieron de esos conceptos de manera creativa para pensar situaciones propias del escenario local. Algunas de las preguntas a las que intentaremos responder son, ¿qué lugar ocupaban los atorrantes en la estructura social desde la perspectiva marxista de El Obrero? ¿Eran considerados la "escoria" de la sociedad, es decir, asimilables al lumpenproletariado de Marx? ¿O constituían en cambio un ejército de reserva para el capital? ¿Qué consecuencias tenía para quienes eran así definidos ser pensados de una forma o de otra? ¿Y qué implicancias tenía para un movimiento obrero en vías de conformación?

El corpus sobre el que trabajaremos se concentra en notas publicadas en el periódico El Obrero durante sus años de existencia (1890-1892). Esta publicación nos interesa particularmente por dos motivos. Por un lado, porque se publicó en el contexto de una crisis en la que, a pesar de tener considerables repercusiones en la pérdida de posibilidades laborales, no estaban dadas las condiciones para interpretar esas vivencias como una falta de trabajo involuntaria. ${ }^{8}$ Por otro lado, por su lectura de la sociedad argentina desde el prisma del marxismo puesto que en las obras de obras de Marx se encuentran elementos fundamentales para la formulación de un no-trabajo forzado (condición de posibilidad, a su vez, para la emergencia, mucho más tardía, del concepto de "desocupado"). ${ }^{9}$ Nos interesa en particular analizar el modo en que las categorías marxistas fueron movilizadas para pensar de un modo diferente las situaciones de falta de

"Sabina Dimarco, "Los socialistas y el problema de la falta de ocupación en la crisis de 1890", Estudios sociales del Estado, vol.2, N4, 2016, 151-180.

7 Pierre Bourdieu, "Las condiciones sociales de la circulación internacional de las ideas", Actas de la investigación en ciencias sociales, vol. 145, 2002, pp.3-8; Horacio Tarcus, Marx en la Argentina. Sus primeros lectores obreros, intelectuales y científicos, Buenos Aires, Siglo XXI, 2007.

8 Dimarco, op. cit.

9 Bénédicte Zimmermann, La constitution du chômage en Allemagne. Entre professions et territoires, Paris, Éditions de la Maison des sciences de l'homme, 2001; Sabina Dimarco, "Marx y el problema de la falta de ocupación", Astrolabio, $\mathrm{N}^{\circ} 17,2016$. 
trabajo en el marco de la crisis de 1890. Con posterioridad a esta breve experiencia, el socialismo no volverá a abrazar ideas propiamente marxistas. ${ }^{10}$

El artículo dialoga con algunas perspectivas de investigación que han tenido un fértil desarrollo en los últimos años. Una de ellas refiere a los estudios de la historia del socialismo argentino, 11 fundamentalmente los que se han ocupado de sus etapas embrionarias (antes de su constitución como partido político) y sus vínculos con el marxismo ${ }^{12}$. Por otro lado, puesto que nos proponemos estudiar la forma en que ciertas categorías fueron movilizadas para pensar contextos y situaciones muy diferentes a las que caracterizaban los ámbitos en que fueron elaboradas, se nutre también de los estudios sobre recepción y circulación internacional de ideas. ${ }^{13}$ Finalmente, dado que este artículo se inserta en un estudio más amplio que se pregunta por configuración de la categoría de desocupado en Argentina, entabla un diálogo con los trabajos que abordan la historicidad de las categorías sociales, y muy particularmente aquellos que analizaron dicha categoría social desde una perspectiva socio-histórica y constructivista. ${ }^{14}$ La pregunta más general que nos llevó a preguntarnos por la forma en que fue problematizada la figura del atorrante refiere a los procesos sociales que dan cuenta de la lenta y progresiva configuración de un nuevo estatuto: el de "trabajador sin trabajo".

El artículo se divide en tres partes. En la primera parte nos concentramos en la recepción temprana de la obra del pensador alemán por parte de los socialistas de El

10 Hernán Camarero, "El Partido Socialista de la Argentina y sus espinosas relaciones con el movimiento obrero: un análisis del surgimiento y disolución del Comité de Propaganda Gremial, 1914-1917", Revista Izquierdas, $\mathrm{N}^{\circ} 22,2015,158-179$.

11 Ricardo Falcón, Los orígenes del movimiento obrero (1857-1899), Buenos Aires, CEAL, 1984; Ricardo Falcón, "Orígenes del movimiento socialista en Argentina", Cuadernos del Ceisal, 2011, № 10, 11-45; Hall Spalding, La clase trabajadora (Documentos para su historia, 1890-1912), Buenos Aires, Galerna, 1970; Jacinto Oddone, Historia del socialismo argentino, Buenos Aires, CEAL,1983; Dardo Cúneo, Juan B. Justo y las luchas sociales en la Argentina, Buenos Aires, Solar, 1997; Hernán Camarero y Herrera, El Partido Socialista en Argentina. Sociedad, politica e ideas a través de un siglo, Buenos Aires, Prometeo, 2005; Camarero, op.cit.; Aricó, La hipótesis de Justo: escritos sobre el socialismo en América Latina, Buenos Aires, Sudamericana, 1999.

12 Horacio Tarcus, op.cit.; Horacio Tarcus, “¿Un marxismo sin sujeto? El naturalista Germán Avé-Lallemant y su recepción de Karl Marx en la década de 1890", Políticas de la Memoria, CEDINCI, N 4, 2003/2004, 71-90; Martínez Mazzola, “Campeones del proletariado. El periódico ‘El Obrero' y los comienzos del socialismo en la Argentina", Políticas de la Memoria. CeDInCI, N4, 2003/2004; Lucas Poy, "Socialismo y anarquismo en la formación de la clase obrera en Argentina: problemas historiográficos y apuntes metodológicos", Archivos de historia del movimiento obrero y la izquierda, $\mathrm{N}^{\circ} 1,2012,1-34$; Lucas Poy, Los orígenes de la clase obrera argentina. Huelgas, sociedades de resistencia y militancia política en Buenos Aires, 1888-1896, Buenos Aires, Imago Mundi, 2015.

13 En el ámbito nacional: Oscar Terán, América Latina, positivismo y nación, México, Katún, 1983; Tarcus, Marx..., op.cit; Mariano Plotkin, Freud en las Pampas, Buenos Aires, Sudamericana, 2003; Jimena Caravaca y Mariano Plotkin, "Publicaciones especializadas y liberalismo periférico. Notas Preliminares sobre la Transmisión de ideas Económicas en Argentina, 1870-1890", Revista de Indias, Vol. 73, N 257, 55-80; Natacha Bacolla y J. Caravaca, "Circulación de ideas en torno a los saberes de Estado", Estudios Sociales del Estado, 2017, vol.3, № 5, 1-11; entre otros.

14 Christian Topalov, Naissance du chômeur, 1880-1910, Paris, Albin Michel, 1994; Robert Salais, N. Baverez y B. Reynaud, L'invention du chômage: Histoire et transformations d'une catégorie en France des années 1890 aux années 1980, Paris, PUF, 1986; Bénédicte Zimmermann, La constitution du chômage en Allemagne. Entre professions et territoires, Paris, Maison des Sciences de l'Homme, 2001; William Walters, Unemployment and government. Genealogies of the social, Cambridge, Cambridge University Press, 2000. 
Obrero. Luego, describimos la manera en que desde este sector se incorporan los conceptos de ejército de reserva y sobrepoblación relativa para pensar la funcionalidad de las situaciones de falta de trabajo y para dar forma a una categoría intermedia entre el trabajo y la vagancia: la de trabajadores sin trabajo. Por último, analizamos qué lugar tenían los atorrantes en la estructura social de acuerdo a la concepción de los socialistas marxistas y si éstos eran interpretados bajo la idea del lumpenproletariado o del ejército de reserva. Buscaremos mostrar que pensarlos de una forma o de otra tiene importantes implicancias políticas en la organización del movimiento obrero.

\section{Marx en las pampas: la realidad local desde la perspectiva de El Obrero}

En su exhaustivo estudio sobre la recepción de Marx en Argentina, Horacio Tarcus señala que las ideas del pensador alemán tuvieron una vertiginosa difusión a nivel mundial durante las últimas dos décadas del siglo XIX y principios del XX, y que la Argentina no fue ajena a ese proceso. ${ }^{15}$ La temprana recepción de ideas marxistas en el país se vincula con la llegada de inmigrantes europeos que portaban consigo experiencias de organización y lucha obrera en sus países de origen y que no en pocos casos llegaban huyendo de la persecución a las ideas libertarias y llevando a cuestas literatura política y contactos con camaradas que les permitían mantenerse relativamente informados. Los primeros indicios de una recepción de Marx en Argentina se remontan a la década de 187016, y en particular a inmigrantes que habían participado de los acontecimientos de la Comuna de París y su exilio los había llevado a Buenos Aires. Los communards franceses llevaron adelante los primeros intentos por establecer núcleos socialistas en el país pero la experiencia fue de corto aliento. ${ }^{17}$ Una segunda recepción remite a los años de 1880, esta vez movilizada por los socialistas alemanes que llegaban huyendo de las leyes antisocialistas de Bismarck. Este grupo de exiliados alemanes, que dio origen al emblemático Club Vorwärts y al periódico que llevó el mismo nombre publicado en idioma alemán, tuvo un papel fundamental en el desarrollo de la primera etapa del socialismo argentino con el suizo José Winiger como figura central. Los hombres del Vorwärts adoptaron los objetivos surgidos de la Segunda Internacional y pusieron en marcha un comité al que se integraron las sociedades gremiales existentes entonces. El llamado Comité Internacional Obrero (CIO), bajo la presidencia de Winiger, fue el encargado de la organización de la manifestación del $1^{\circ}$ de mayo en 1890, fecha declarada en el Congreso de 1889 jornada de protesta mundial de los trabajadores, y formuló el primer petitorio de leyes de protección obrera en ser presentado al Congreso Nacional. Dicho petitorio retomaba las demandas centrales del Congreso de París, aunque también incorporaba reclamos relativos a las especificidades nacionales. Desde ese comité se impulsó la formación de la primera Federación Obrera y de su órgano de difusión, El Obrero, editado en español. Al poco tiempo de haberla promovido, el Vorwärts dejó de formar parte de la Federación.

\footnotetext{
15 Tarcus, Marx..., op.cit.

16 Tarcus, idem; Poy, Los orígenes... op.cit.

17Falcón, Los orígenes..., op.cit.; Tarcus, Marx..., op.cit.
} 
A instancias del CIO, otro alemán, el ingeniero Germán Avé-Lallemant, quien para entonces ya era un destacado referente intelectual del socialismo en ese período inicial, fue nombrado para dirigir el nuevo periódico. Lallemant, quien había sido hasta entonces un asiduo colaborador del Vorwärts, constituye una figura particularmente relevante para nosotros puesto que fue a través de él, como sostiene Tarcus, que empezaron a difundirse en estas tierras las ideas de Marx. En efecto, Tarcus menciona que es posible que las pocas notas que el periódico en alemán había dedicado a Marx y Engels fuesen autoría de Lallemant y que probablemente, para la década de 1890 cuando se pone al frente del órgano de difusión de la Federación, fuese la única persona en el país familiarizada con la obra de estos pensadores. Así las cosas, este ingeniero alemán instalado en San Luis fue quien dio a la nueva publicación la impronta marxista que se sostendría incluso luego de su alejamiento del cargo de director poco tiempo después. A pesar de dejar ese cargo, nunca dejó de ser un colaborador activo en la misma.

De este modo, a instancias de Lallemant, El Obrero. Defensor de los intereses de la clase proletaria devino el primer intento por analizar la realidad nacional desde una perspectiva marxista. Realidad nacional, por otra parte, de cuyo conocimiento el ingeniero alemán ya había dado considerables muestras en producciones previas. Pero a pesar de esa importante labor previa, y esto nos interesa subrayarlo, Tarcus señala que con anterioridad a 1888 no se hallan en sus escritos y reflexiones o indicios de una conceptualización en términos marxistas. $\mathrm{Y}$ si es posible rastrear en aquel año las primeras referencias a conceptos provenientes del marxismo, fue recién en 1890, con la publicación de El Obrero, que Lallemant desarrolló su "profesión de fe marxista". ${ }^{18}$ Aunque no está claro cuál fue la vía a través de la cual Lallemant tomó contacto con las obras de Marx y Engels, este autor plantea dos posibilidades: que haya tenido acceso a la literatura marxista y socialistas a través de la difusión que llevó adelante el Vorwärts, o que haya recibido las obras por la vía de una correspondencia directa con Alemania. ${ }^{19}$ Cualquiera haya sido el caso, sus notas fueron la primera plataforma desde la que se movilizaron conceptos marxistas para pensar esos años de 1890 en Argentina.

Como es sabido, esa realidad nacional en el marco de la cual se llevó adelante la publicación se caracterizó por estar atravesada por una doble crisis, económica y política. La crisis política que derivó en la denominada "Revolución del Parque" y en la renuncia de Juarez Celman va a estar muy presente en la publicación, pero nos interesa aquí en particular la lectura realizada desde el periódico de la crisis económica y de su impacto sobre el empleo. Ciertamente, el incremento de la emigración era sin dudas una de consecuencias de la crisis económica y su incapacidad para generar puestos de trabajo. ${ }^{20}$ Pero también lo era el crecimiento del número de personas que deambulaban por las calles de Buenos Aires en busca de algún empleo o sustento, o que se aventuraban a recorridos más lejanos en busca de oportunidades de colocación en otros parajes. Todos ellos eran caracterizados en la prensa, las memorias municipales, los informes policiales, las novelas y los diarios de viajero como linyeras, vagabundos, mendigos o atorrantes.

18Tarcus, Marx..., op.cit,.186.

19 Idem

20 Poy, Los orígenes... op.cit. 
Fue justamente en ese contexto de crisis y dificultades de empleo cuando el término atorrante se extendió y consolidó en el ámbito porteño, como vimos al comienzo, y las acusaciones de vagancia se actualizaron para señalar a quienes se movilizaban de un lugar a otro. El uso de esos términos, y la legitimidad con la que contaron en el ámbito público, ponen de manifiesto que esas dificultades del mercado para generar empleo no habían dado lugar, en 1890, a un cambio en las representaciones sociales respecto de quienes no contaban con ocupación demostrable, ni a un replanteo de las modalidades de intervención. Esa forma de nombrar el problema y la intensificación de las respuestas represivas, por el contrario, dan cuenta de la continuidad de una perspectiva que condenaba toda experiencia de falta de trabajo con independencia de las causas puesto que se la pensaba, incluso en el contexto de la crisis, como una marginalidad voluntaria en un país que, se decía, ofrecía oportunidades para todo aquel dispuesto a tomarlas.

Ahora bien, en ese mismo contexto, los socialistas de EO brindaron a través de diversas notas una mirada diferente sobre aquella figura urbana. Puesto que el atorrante, como señalamos en otra oportunidad, ${ }^{21}$ se constituyó en una vía de entrada para que los socialistas disputaran las representaciones hegemónicas sobre la falta de trabajo, importa preguntarse de qué modo la perspectiva marxista que caracterizaba a esta publicación contribuyó a delinear esa interpretación alternativa de aquella figura, y a través de ésta del problema de la falta de trabajo en Argentina.

Por otra parte, si bien es cierto, como ha señalado Poy, que esos años de crisis fueron un período de reflujo de la conflictividad obrera y en el que la lucha por la defensa de las fuentes de la trabajo ganó peso en detrimento del reclamo salarial, 22 este análisis nos permite indagar en otras formas que adoptó la puja por la constitución de una identidad obrera en esta etapa embrionaria. En particular, la disputa por la definición de los problemas obreros, de una parte, y por la demarcación de los límites mismo de la categoría de "trabajador" de otra.

\section{La funcionalidad de los "sin trabajo": ¿ejército de reserva del capital?}

Desde sus primeros números El Obrero intentó erigir a la falta de trabajo un tema de relevancia para el naciente movimiento obrero. En esa dirección se volcaron considerables esfuerzos para instalarlo entre las preocupaciones públicas. ${ }^{23} \mathrm{~A}$ comienzos de enero de 1891 desde las páginas del periódico se difundió la convocatoria del CIO al primer "meeting de trabajadores sin ocupación". Se lo hizo a través de una extensa nota que constituye en sí misma una forma de instalar el tema tanto en la agenda gubernamental y mediática como en la de los propios trabajadores. En ella, se buscaba dar cuenta de la magnitud del problema y fundamentalmente de sus efectos punzantes para los trabajadores; se argumentaba además acerca de la necesidad de manifestarse masivamente para dar visibilidad al fenómeno. ${ }^{24}$ En esa primera nota que trata in extenso la cuestión,

\footnotetext{
21 Dimarco, “Los socialistas...", op.cit.

22 Poy, Los orígenes... op.cit.

23 Op.cit.

${ }^{24}$ Este tema lo he trabajado en Dimarco, "Los socialistas...", op.cit..
} 
pero que no había sido escrita por el grupo redactor de $E O$, no hay referencias a términos marxista. Prevalece más bien un registro moral de interpretación del fenómeno que apuntaba a generar empatía con quienes eran definidos como los "sin trabajo". 25

Un mes más tarde, la cuestión de la falta de trabajo aparece interpretada en clave marxista; esto es, centrada en la idea de la necesidad sistémica de la existencia de un "ejército de reserva" funcional al capital. En el mencionado petitorio presentado al Congreso de la Nación por el CIO se encontraba como un punto importante, que provenía de las resoluciones de la Segunda Internacional, el reclamo por la jornada laboral legal de ocho horas. En la justificación, publicada en el periódico, se mencionaba el problema de la falta de ocupación como uno de los objetivos fundamentales a los que apuntaba la demanda de reducción horaria. Marx señaló fundamentalmente dos elementos que nutrían a la sobrepoblación relativa: "los obreros desplazados por la maquinaria [que] se ven lanzados del taller al mercado de trabajo, donde van a aumentar el número de las fuerzas de trabajo disponibles para la explotación capitalista" y aquellos expulsados de sus ocupaciones en períodos de crisis o "en las épocas de negocios flojos". ${ }^{26}$ Estos dos elementos eran también evocados para justificar la necesidad de una jornada legal de trabajo en Argentina, "la introducción de máquinas perfeccionadas por un lado, y la escasez momentánea del trabajo", crea una "superabundancia de la población obrera, reduciendo constantemente el número de obreros empleados en el taller, arrojándose a la calle y creando una sobrepoblación obrera artificial, llamada el ejército de reserva del capital". ${ }^{27}$ Las resonancias de las palabras de Marx son evidentes. Sin embargo, no se desatiende lo que estos socialistas consideran una particularidad local: en Argentina, agregaban, con tantos trabajadores disponibles y dispuestos a aceptar magros salarios, los capitalistas recurrían más a la sobrecarga de trabajo de los obreros que a la capitalización. ${ }^{28}$ En este sentido, a pesar de que se lo menciona en un primer momento, en el desarrollo de la justificación el problema de la mecanización no aparecía como un problema propio de la realidad local.

En cuanto a la funcionalidad de esa masa de obreros disponibles -de la cual no se daba cuenta en el artículo que convocaba al mitin-, decían: "Este ejército de reserva del capital es el arma terrible del capitalista para rebajar los salarios a su mínimum, y prolongar la jornada a su máximum. Por lo tanto: el interés primordial de la clase obrera mientras exista la sociedad burguesa, es reducir todo lo posible ese ejército de reserva del capital (...)". ${ }^{29}$ En lo referente a las soluciones propuestas, una vez más se observa una combinación entre las propuestas emanadas de la Segunda Internacional -la jornada de ocho horas- con otras de clara impronta más local, en particular, la cuestión de la emigración. La interpretación del problema de la falta de trabajo como resultante de un exceso de inmigración en relación a la cantidad de trabajo disponible fue tempranamente incorporada por los socialistas argentinos dando cuenta de una problemática más

\footnotetext{
25 "Meeting de trabajadores sin ocupación", El Obrero, 9 de enero de 1891.

26 Karl Marx, Manuscritos: economía y filosofía, Madrid, Alianza, 1999, 391.

27 "Presentación de la Federación Obrera al Congreso. La jornada legal de ocho horas", El Obrero, 14 de febrero de 1891.

28 Idem.

29 Idem.
} 
localizada. Este tema aparecía en El Obrero - y se mantendría en publicaciones posteriorescon cierta insistencia ligado a la demanda de ayuda estatal para el regreso de los trabajadores sin ocupación a sus países de origen y el control de la inmigración "artificial" (es decir, la que consideraban promovida por las agencias estatales con intención de influir en los salarios y a la que contraponían a la inmigración "espontánea"). A lo largo de las publicaciones fueron proponiendo además otra serie de medidas tendientes a resolver este tema, entre ellas, la demanda de creación de colonias agrícolas, la implementación de obras públicas y la creación de una Bolsa de Trabajo gratuita a semejanza de la Paris.

Ejército de reserva y sobrepoblación relativa son las categorías desde las que este sector del socialismo va a buscar explicar la situación de aquellas personas que, tanto en la ciudad como en el sector rural, no encontraban ocupación que les permitiera ganar un salario. En ese momento en el que la relación al trabajo se pensaba en forma binaria (trabajo/vagancia), traducir el no-trabajo en términos de ejército de reserva tenía un potencial político de gran valor: todos aquellos que se encontraban transitoriamente sin ocupación, por fuera de la relación laboral, podían ser pensados como "trabajadores sin trabajo" y formar parte del universo obrero al que se orientaban las acciones de estas organizaciones. Cuando Marx conceptualiza al ejército de reserva lo hace ubicándolo no como una exterioridad a las relaciones de producción sino, justamente, como una continuidad respecto de éstas; incluso, como un sector fundamental para su funcionamiento. ${ }^{30}$ Desde esa perspectiva, rompe con la diferencia que en su época se presentaba como casi ontológica entre "trabajadores" y "vagos": en su descripción del ejército de reserva queda claro que son los mismos proletarios quienes pasan, según los momentos del ciclo económico, del ejército activo al de reserva y viceversa. La sobrepoblación, dirá Marx, no deriva de un "acrecentamiento excesivo absoluto de la población obrera" sino "de la conversión de la misma en relativamente supernumeraria". ${ }^{31}$ Inscribir el tema de la falta de trabajo en la perspectiva de la sobrepoblación relativa le permite a este sector del naciente socialismo argentino incorporar al tema como un reclamo propio y disputar la idea, sólidamente instalada, que responsabilizaba a quienes no trabajan. Así, planteaban que: "En las provincias hay una sobrepoblación relativa, que no halla trabajo y no tiene que comer, sumida en la mayor miseria". 32 Pero a su vez, no se trataba de una mera aplicación de categorías al contexto nativo sino de una readaptación de las mismas a la situación de la Argentina agroexportadora en la que el problema no pasaba por la necesidad de un ejército industrial sino agrario de reserva que permitiese atender a las necesidad cíclicas del mercado: "Estos pedidos de trabajadores hacen los gran [sic] hacendados capitalistas, para formar un ejército de reserva agricultor, que pertenece al capitalista de una manera tan absoluta como si lo hubiese educado y disciplinado á espensas [sic] suyas: ejército que provee a sus necesidades variables de trabajo, la materia humana siempre explotable y siempre disponible".33 Si bien la definición es casi calcada de

\footnotetext{
30 Dimarco, Marx..., op.cit.

31 Karl Marx, El Capital, T. 1, vol. 3, Buenos Aires; Siglo XXI, 789.

32 "Se necesitan 2487 trabajadores para engañarlos", El Obrero, 27 de junio de 1891.

33 Ídem.
} 
aquella que brindara Marx en El Capital, en este caso sería la burguesía terrateniente la gran beneficiada por la existencia de este "sobrante de población":

Por esta sobrepoblación relativa el estanciero tiene en su mano el de bajar los salarios a un mínimo terrible. Tenemos noticias de todas las provincias y en todas hay una sobrepoblación sin trabajo. ¡No se dejen engañar proletarios! Atención y cuidado con el fraude oficial!34

No hay, no obstante, en ningún momento una descripción o definición de las situaciones que entrarían en la sobrepoblación relativa, como sí se encuentra en la obra de Marx. ${ }^{35}$ Pero lo que se deduce de las páginas del periódico es que, como esta última, para los socialistas de EO se componía también de todos aquellos que no tenían ocupación o que la tenían de forma inestable u ocasional. Esta última forma de relación laboral estaba, como es bien conocido, muy extendida en esa época. ${ }^{36}$ Además, según se desprende de algunas notas, estaba conformada también por los estratos sociales más "degradados", lo que Marx llamó "la esfera el pauperismo" y al que definió como el "sedimento más bajo de la sobrepoblación relativa". ${ }^{37}$ Desde la perspectiva de estos socialistas vernáculos, a los "sin trabajo" se los describía como personas desesperadas, degradadas y dispuestas a grandes esfuerzos con tal de llevar un plato de comida a su casa: "Diez mil esclavos de la miseria que atormentados por el hambre, por la menesterosidad la indigencia propia y de los de su familia quisieran trabajar en cualquier trabajo, sea donde fuese, con tal de ganar tanto como para poder dar de comer a sus hijos" 38

Ahora bien, en la obra del pensador alemán, esa última esfera de la sobrepoblación relativa presenta límites muy difusos con su concepción del lumpenproletariado. Si atendemos a su composición sociológica, las diferencias son opacas: el pauperismo, es decir, ese último estrato de la sobrepoblación relativa, se compone de tres situaciones diferentes: las dos primeras refieren a las personas aptas para el trabajo que engrosan sus filas en épocas de crisis y a los huérfanos e hijos de indigentes; ambos pueden ser absorbidos por el "ejército activo" en períodos de reactivación. La tercera, en cambio, incluye, en sus palabras, a "personas degradadas, encanallecidas, incapacitadas de trabajar" que forman "el hospicio de inválidos del ejército obrero activo y el peso muerto del ejército industrial de reserva" (Marx, 2004.a: 802). A pesar de estas definiciones, Marx lo ubica formando parte de la sobrepoblación relativa de la cual, en cambio, deja explícitamente afuera al lumpenproletariado.

\footnotetext{
34 "Se necesitan...", El Obrero, op.cit.

35 Recordemos que la sobrepoblación relativa en Marx adopta tres formas: fluctuante, latente y estancada (Marx, íbidem, 797), lo que en términos de situaciones concretas implica a los obreros expulsados de la producción en los ciclos económicos en baja, a los trabajadores rurales en vías de metamorfosearse en población manufacturera, trabajadores irregulares como el trabajador a domicilio, entre otros.

36 Hilda Sábato y Luis Alberto Romero, Los trabajadores de Buenos Aires: la experiencia del mercado, 1850-1880, Buenos Aires, Sudamericana, 1992; Mirta Lobato, “Los trabajadores en la era del 'progreso'” en Lobato, Mirta (dir.), El progreso, la modernización y sus límites (1880-1916)", Nueva Historia Argentina, Vol. 5, Buenos Aires, Sudamericana, 2000, 464-506.

37 Marx, El Capital..., op.cit., 802.

38 "Meeting...", El Obrero, op.cit.
} 
En efecto, cuando menciona las distintas formas que adopta la sobrepoblación relativa aclara: "prescindimos aquí de vagabundos, delincuentes, prostitutas, en suma, del lumpenproletariado propiamente dicho" (Marx, 2004.a: 802); y en La lucha de clases en Francia define al lumpen como "una masa bien deslindada del proletariado industrial" formado por "rateros y delincuentes de todas las clases, que viven de los despojos de la sociedad, gentes sin profesión fija, vagabundos, gens sans feu et sans aveu, que difieren según el grado de cultura de la nación a que pertenecen, pero que nunca reniegan de su carácter de lazzaroni". ${ }^{39}$. De este modo, entre esas categorías movilizadas por Marx para dar cuenta de las situaciones de ausencia de relación laboral o de "semi-ocupación", la sobrepoblación relativa (con todas sus esferas, incluida la del pauperismo) constituye, a diferencia del lumpenproletariado, un sector productivo al margen del trabajo por las características del sistema de producción capitalista. ${ }^{40} \mathrm{El}$ lumpen en cambio, en tanto que improductivo, se encuentra excluido de la clase obrera y en más de una oportunidad son presentados por Marx como una infra-clase, "la basura de todas las clases". ${ }^{41}$ Así, mientras que quienes se encuentran en la sobrepoblación relativa, aún en su fracción más degradada, son definidos por Marx como "víctimas de la industria, cuyo número se acrecienta con la maquinaria peligrosa, la expansión de la minería, de las fábricas químicas, etc."), el lumpenproletariado representa la imagen del parasitismo.42 En esa búsqueda por diferenciar al lumpenproletariado del proletariado (incluido el ejército de reserva), Marx no escatima en la descripción de los primeros en criterios que en su época, y desde mucho antes, se utilizaban para perseguir y reprimir la "vagancia", entre ellos la falta de trabajo estable y de domicilio fijo. 43

Teniendo esto en cuenta resulta significativo que el término lumpenproletariado no haya sido utilizado por los socialistas de El Obrero para hablar de la falta de trabajo. Podría pensarse entonces, como sugiere Martínez Mazzola, que el término atorrantismo es la calificación autóctona para lumpenproletariado. ${ }^{44} \mathrm{El}$ uso del término atorrante para dar cuenta de la vida sin salario sí es frecuente en el periódico. Sin embargo, como veremos en el próximo apartado, entre la forma en que los marxistas argentinos piensan al atorrante y la manera en que Marx concibe al lumpenproletariado hay una diferencia sustancial que refiere, justamente, a la posición que ocupan en la clase obrera.

\footnotetext{
39 Karl Marx, El dieciocho brumario de Luis Bonaparte, Buenos Aires, Need, 1998, 62.

40 La producción del pauperismo "está comprendida en la producción de la pluspoblación, su necesidad en la necesidad de ésta, conformando con la misma una condición de existencia de la producción capitalista y del desarrollo de la riqueza" (Marx, El Capital..., op.cit,803).

41 Marx, El dieciocho brumario de Luis Bonaparte, Buenos Aires, Need, 1998, 69.

42 Nicholas Thoburn, "Difference in Marx: the lumpenproletariat and the proletarian unnamable", Economy and Society, Vol. 31, N³,2002, 434-460.

43 El lumpenproletariado está formado por "gentes sin profesión fija, vagabundos, gens sans feu et san aveu", como ya mencionamos.

44 Martínez Mazzola, op.cit.
} 


\section{Atorrantes: ¿lumpenproletariado o ejército de reserva?}

En una nota de noviembre de 1891 la asociación entre atorrantismo y lumpenproletariado parece, aunque nunca sea nombrado de ese modo, bastante clara. En "Pueblo y proletariado"45 plantean que antiguamente, antes de la Revolución Francesa, la palabra "pueblo" aludía a la gran masa de la población "en contraposición al Gobierno y a los estados privilegiados de la "Nobleza" y del "Clero". Se trataba entonces de una categoría amplia y heterogénea que incluía indiferenciadamente "a una mezcla de varias clases de habitantes, capitalistas, paisanos o labradores, pequeños burgueses, proletarios, miembros del estado ideológico, a que pertenecen los médicos, abogados, ingenieros, artistas, etc., y atorrantes". ${ }^{46} \mathrm{Y}$ aclaraba: "Estos ciudadanos, todos en conjunto, formaban el 'Pueblo'".47 Con la caída del absolutismo, dirán, se quebró aquello que los mantenía unidos que era la lucha por los derechos políticos como interés común y quedó en evidencia que el pueblo " se compone de diferentes clases con intereses antagónicos, y no pueden mejorar los intereses de una clase sin depravar los de la otra". Por eso, explican, cuando los socialistas hablan de "pueblo" hacen referencia solamente a uno de esos sectores que se encontraban reunidos en la concepción tradicional -y que seguía siendo el uso que, según ellos, hacían los "piliticastros de la época histórica de la producción capitalista". Ese sector era el del proletariado que representaba, de acuerdo a su concepción, sólo una parte del pueblo, e incluso, aclaraban, una parte minoritaria. Lo que resulta significativo en esa contraposición entre "pueblo" y "proletariado" es este intento explícito por demarcar al interior de una categoría heterogénea un sector específico, el de la "verdadera clase productora", los trabajadores. Y, fundamentalmente, que esa delimitación se llevase a cabo a través de una exclusión: los pequeños burgueses y labradores arruinados que no necesariamente pasarán a formar parte del proletariado sino que "caen en el atorrantismo, otros se vuelven mercachifleros, buhoneros o pulperos".48 Recordemos que los atorrantes formaban parte de la amplia categoría de "pueblo" tal como la habían definido en la primera parte del texto.

Es entonces a través de esa demarcación al interior de la antigua categoría que fue tomando forma, según este texto, la renovada categoría de "proletariado" como la clase que "sabe que es su sagrada misión de [sic] elevar a la humanidad a un grado superior de cultura, de grandeza"49. En esa delimitación entre la clase productiva (proletariado) por un lado, y los atorrantes por otro, encontramos claras reminiscencias a la distinción entre proletariado y lumpenproletariado que en la obra de Marx opera liberando a la primera categoría de la condena moral que tradicionalmente se le asociaba y lo hacía volcando todo su peso estigmatizante sobre la segunda. ${ }^{50}$

\footnotetext{
45 "Pueblo y proletariado", El Obrero, 28 de noviembre de 1891.

46 Idem .

47 Idem.

48 Ídem..

49 Ídem.

50 Thoburn, op.cit; Huard Raymond, "Marx et Engels devant la marginalité: la découverte du lumpenproletariat", Romantisme, N59, 1988, 5-17; Dimarco, Marx..., op.cit..
} 
Esa no va a ser la única ocasión en que la figura del atorrante aparezca mencionada como una figura límite, es decir, en los márgenes del universo del proletariado y asociada a la ausencia de moralidad e incluso a la depravación. Por momentos, la referencia a la ebriedad y la delincuencia da cuenta de una imagen del atorrante que se asemejaba bastante a lo que ellos mismos describían como la representación burguesa de esa figura. Sin embargo, no hay que confundirse. En el caso del socialismo no se trataba de una crítica o condena en términos morales de quienes eran definidos como atorrantes sino de una denuncia al sistema económico y social que los "obligaba" o "impelía" a esa situación: "á menudo [se ven] obligados á implorar la caridad agena (sic) por un pedacito de pan, y muchas veces impelidos al robo y al atorrantismo". ${ }^{11}$ Quienes eran así arrojados a la miseria y a la degradación social no eran quienes rehuían al esfuerzo de ganarse su propio sustento sino "un gran número de trabajadores, que andan en busca de una ocupación"52. Desde esta perspectiva entonces, el atorrantismo, incluso si podía implicar recurrir a la mendicidad y al delito, era considerado una consecuencia de la falta de trabajo o de un trabajo que no alcanzaba para el propio sustento y el de la familia y no una categoría deslindada del mundo obrero.

Esto suponía una interpretación diferente a la generalizada en la época -e incluso a aquella que con frecuencia llega hasta nuestros días-, en la que la explicación, a pesar de algunas vacilaciones, se trasladaba de las causas psicológicas/morales a las sociales/sistémicas. En octubre de 1891, cuando la crisis se hacía sentir con dureza, El Obrero publicó una nota titulada "Los atorrantes" en la que cuestionaban la connotación negativa atribuida por los burgueses al término: "En la prensa burguesa se está expresando diariamente más la tendencia de recurrir a la policía en demanda de auxilio, contra los vagamundos, hombres sin trabajo, y pordioseros, que los gordos y highlifers del país tratan con el mayor menosprecio y altanería de atorrantes, sinónimo de pobre depravado y relajado"53 y denunciaban que por lo general no se buscaba atender a "las verdaderas razones del problema". En esa nota, dedicaron un espacio importante al trabajo presentado por un médico alemán en un congreso de medicina realizado en Amberes. En ese trabajo, según explicaban, el especialista presentó los "caracteres" que explicarían las causas de prácticas como la criminalidad, la prostitución y el atorrantismo. Se concentraba en lo que denominaba las causas psicológicas y fisiológicas del atorrantismo o "vagabondage", entre las que se mencionaban cuatro "caracteres especiales":1. la "follonería, o sea, la aversión al trabajo que tiene su causa en una debilidad de los nervios [...] y que es hereditaria";2. la "falta de reflexión y lijereza (sic) de acciones"; 3. la "claustrofobia, o sea la aversión a los espacios estrechos"; 4. "la intranquilidad sicológica o de alma [...] tiene su origen en una excitación nerviosa". 54 Como vemos, a pesar del halo de sofisticación que presentaba el estudio en cuestión, no se trataba sino que de una búsqueda por revestir de argumentos supuestamente científicos la antigua atribución de causas individuales a las situaciones de ausencia de trabajo. Los socialistas de EO se apoyaron en ese estudio

51 "El derecho al trabajo", El Obrero, 16 de enero de 1892.

52 Idem. El subrayado es nuestro.

53 "Los atorrantes", El Obrero, 24 de octubre de 1891.

54 Ídem. 
internacional y "científico" porque les permitía argumentar contra la criminalización de dichas "prácticas": dado que las conclusiones establecían que quienes se encontraban en esa situación estaban imposibilitados de ganarse la vida por sus propios medios, tenían derecho a la caridad pública. Pero lo que nos interesa particularmente es que, a pesar de que el estudio del médico berlinés era citado como fuente de autoridad en el tema, los socialistas de EO concluyen distanciándose claramente de aquella interpretación para proponer en cambio una explicación que allí no estaba contemplada y que remitía, según ellos, a "las causas profundas" del problema. "El Congreso -planteaban- no ha tomado en consideración las barbaridades sociales de la actualidad al tratar sobre el atorrantismo".55 De este modo, sin desacreditar totalmente las explicaciones del médico -puesto que consideraban que en no pocos casos el atorrantismo podía deberse a una "degeneración psicológica"- afirmaban: "no por eso dejaremos de sostener nuestra opinión, que la principal causa del atorrantismo, de la criminalidad y de otros fenómenos sociales semejantes que son un oprobio para la civilización de nuestra época, se halla en las condiciones irracionales económicas de la actualidad, y nacen del capitalismo y de la producción capitalista". 56

En otras notas la referencia a los atorrantes como "hombres sin trabajo", que buscaban ocupación, pero no conseguían por razones ajenas a su responsabilidad, era más directa. Mencionaban, incluso, al atorrante como una "invención" burguesa, frente a una realidad en la que el trabajo escaseaba. Quienes la burguesía define de ese modo degradante, decían, "no saben en dónde buscar el pan del día".57 De este modo, los atorrantes no constituían, para el grupo socialista editor de EO, un sector -retomando los términos de Marx que definen al lumpenproletariado- deslindado del proletariado industrial. Las categorías de sobrepoblación relativa o ejército de reserva resultaban más apropiadas para describir a esa figura desde su perspectiva. Así, por ejemplo, en agosto de 1891, denunciaban una vez más que "los diarios en el servicio de la burguesía y pagos por ella, están empeñadísimos en hacer creer que faltan brazos para la agricultura y la industria en el país" ocultando que "en realidad existe una sobrepoblación relativa". Y aclaraban que era a esos "miles de hombres sin trabajo, sin hallar trabajo" a quienes la burguesía llamaba "atorrantes o vagabundos" y castigaba por la vía represiva.

Ahora bien, pensarlos en términos de sobrepoblación relativa tiene dos consecuencias muy importantes, una relativa a la conformación del movimiento obrero y la otra relacionada con la demanda de soluciones. El primer punto resulta central puesto que las últimas décadas del siglo XIX eran las de la progresiva conformación de una clase obrera organizada en la que socialistas y anarquistas se disputaban su representación. Una idea de los atorrantes más cercana a la del lumpenproletariado, es decir, pensados como una infraclase completamente deslindada del sector obrero, conducía a desentenderse respecto de su situación. En cambio, presentarlos como un ejército de reserva a la espera del momento en que la burguesía (los grandes hacendados fundamentalmente en el caso argentino) requiriera nuevamente de sus servicios era también pensarlos como parte de la clase

\footnotetext{
55 Ídem.

56Ídem.

57El Obrero, 17 de octubre de 1891.
} 
obrera. Los atorrantes eran, para este sector del socialismo, trabajadores sin trabajo. O, en otros términos, trabajadores a los que el sistema no brinda posibilidades de empleo.

De ahí se desprende una consecuencia fundamental: el problema de la falta de trabajo debía ser no sólo un problema de cada gremio en particular sino un problema obrero, objeto de sus luchas. Los "sin trabajo", en tanto, constituían parte de la identidad obrera en formación: no "atorrantes" que se autoexcluían del mundo del trabajo sino "trabajadores" expulsados a la fuerza de éste.

\section{Reflexiones finales}

Centrándonos en un sector específico del socialismo - el de los socialistas marxistas nucleados en torno al periódico El Obrero- y en un periodo de crisis económica con considerables consecuencias en las oportunidades laborales -la crisis de 1890- en este artículo analizamos las disputas de sentido entabladas desde el socialismo sobre la popular y estigmatizada figura del "atorrante". Buscamos, de este modo, profundizar en el análisis de un tema que apenas habíamos esbozado en un artículo previo ${ }^{58}$ referido al papel que esa disputa jugó en la configuración de una representación del no-trabajo que se alejaba de las representaciones dominantes en su época. Nos interesó en particular indagar en el papel que en ese proceso pudieron jugar los conceptos marxistas a los que este sector del socialismo adscribía. Así, la figura del atorrante, término cuyo uso se había extendido mucho en esos años, nos sirvió de vía de entrada para el estudio del modo en que los socialistas marxistas confrontaron con las representaciones "burguesas" de la falta de trabajo.

Mostramos entonces que, para este sector del socialismo, quienes eran habitualmente tildados de atorrantes no constituían un sector aislado del movimiento obrero; en otros términos, no eran pensados desde la noción marxista de lumpenproletariado, es decir, como un sector deslindado de la clase trabajadora. Al contrario de lo que dejarían entrever algunas descripciones del propio periódico, eran pensados en términos de ejército de reserva o sobrepoblación relativa, lo que los ubicaba en la estructura social formando parte de la clase obrera, a quienes los socialistas se proponían representar. La perspectiva marxista permitía también disputar una idea más profunda y muy arraigada en estas tierras según la cual la falta de trabajo era un problema individual y atribuible a cuestiones morales y psicológicas, y ubicarlo en cambio como un problema relativo al funcionamiento social y económico. Un problema, incluso, inherente y funcional al sistema capitalista que se encontraba entonces en pleno desarrollo. Esto, a su vez, los llevaba a disputar las medidas implementadas y a exigir respuestas que atendieran a la especificidad del problema.

A partir del análisis realizado tratamos de mostrar que no fue casual que los primeros cuestionamientos a esas formas tan asentadas en que se pensaba la falta de trabajo proviniesen de estos socialistas que se encontraban intelectualmente vinculados a lo que ocurría en otros lugares del mundo y en particular al marxismo internacional. En el continente europeo, la puesta en forma de la idea de un no-trabajo involuntario por parte

\footnotetext{
58 Dimarco, 2016a, op.cit.
} 
de los reformadores sociales se estaba llevando adelante justamente en ese mismo período. ${ }^{59}$ Esa última década del siglo XIX fue, como mostraron varios autores, la de la "invención" del desocupado moderno. Pero antes de que ello sucediera, la obra de Marx había dado algunos pasos importantes en ese sentido. Bénédicte Zimmermann mostró que los análisis de Marx y Engels, sin llegar a conceptualizar al desocupado moderno, fueron de los primeros en proponer un desplazamiento a la hora de pensar la cuestión de la pobreza pasando del registro moral al registro económico. Sin este desplazamiento en la mirada sobre la pobreza, dirá la autora, la situación "sin trabajo" no podría haberse convertido en "desocupación". Las premisas de los pensadores alemanes constituyen, dirá la socióloga alemana, un punto de apoyo importante para las tentativas ulteriores de especificación del no-trabajo por causa económica. En este sentido, insistimos, no resulta casual que desde este sector del socialismo se dieran los primeros pasos en la confrontación con la representación tan sólidamente instalada que veía en toda forma de no-trabajo un problema moral y no económico. $\mathrm{Y}$ si los funcionaros e intelectuales reformistas argentinos no tomaron este tema sino varias décadas después, los socialistas argentinos tuvieron un papel importante y precoz en ese proceso.

Ahora bien, el análisis de la forma en que se toma desde esta publicación la figura del atorrante nos permite ver que no hubo, en el caso de los socialistas argentinos, ninguna conceptualización que permitiese pensar un afuera del mundo del trabajo en personas en condiciones de trabajo (lo que en la época todavía eran llamados pobres válidos). Marx, como hemos visto, había forjado su categoría de lumpenproletariado como una forma de demarcación -"por abajo" y como contrafigura- de la clase obrera. En el caso de los socialistas argentinos de EO no hemos hallado ninguna categoría que cumpla esa función. Podía haber casos aislados, como mencionan en alguna oportunidad, en que la falta de trabajo respondiese a una falta involuntaria. Pero el atorrante, decían, figura paradigmática para la representación de esa idea de un no-trabajo voluntario en personas válidas a fines del siglo XIX no representaba la antítesis del trabajador sino parte de una clase trabajadora inestable que un día podía tener trabajo y al otro ser expulsado al ejército de reserva (fundamentalmente agrario en el caso local) y etiquetado como "vago" o "atorrante" por la propia burguesía que los había producido y que los necesitaba.

Mencionamos también que de esa caracterización se desprende una consecuencia política de importancia en ese momento de embrionario de constitución de una identidad obrera: si bien el problema de la falta de trabajo no forma parte de las peticiones presentadas al Congreso por el $\mathrm{CIO}$, los socialistas de $\mathrm{EO}$ entenderán que se trata de un tema al que hay que dar visibilidad y constituir en un activo para la movilización obrera.

\section{Bibliografía citada}

Aricó, José, La hipótesis de Justo: escritos sobre el socialismo en América Latina, Buenos Aires, Sudamericana, 1999

Bourdieu, Pierre, "Las condiciones sociales de la circulación internacional de las ideas", Actas de la investigación en ciencias sociales, vol. 145, 2002.

\footnotetext{
59 Topalov, op. cit.
} 
Camarero, Hernán, “El Partido Socialista de la Argentina y sus espinosas relaciones con el movimiento obrero: un análisis del surgimiento y disolución del Comité de Propaganda Gremial, 1914-1917", Revista Izquierdas, № 22, 2015, pp. 158-179

Camarero, Hernán y Herrera, El Partido Socialista en Argentina. Sociedad, política e ideas a través de un siglo, Buenos Aires, Prometeo, 2005

Cúneo, Dardo, Juan B. Justo y las luchas sociales en la Argentina, Buenos Aires, Solar, 1997

Daireaux, Emile, La vie et les moeurs a La Plata, Paris, Hachette, 1888.

Dimarco, Sabina, "Los socialistas y el problema de la falta de ocupación en la crisis de 1890", Estudios sociales del Estado, vol.2, N4, 2016

Dimarco, Sabina, "Marx y el problema de la falta de ocupación", Astrolabio, № 17, 2016.

Falcón, Ricardo, Los orígenes del movimiento obrero (1857-1899), Buenos Aires, CEAL, 1984

Falcón, Ricardo, "Orígenes del movimiento socialista en Argentina", Cuadernos del Ceisal, 2011, N 10 , pp. 11-45

Gobello, José, Lunfardía. Acotaciones al lenguaje porteño, Buenos Aires, Ed. Dunken, 2001.

Gobello, José y Bossio, Jorge Alberto, El Atorrante, Buenos Aires, Ediciones del Candil, 1968.

Huard, Raymond, "Marx et Engels devant la marginalité: la découverte du lumpenproletariat", Romantisme, N 59, 1988, 5-17.

Martínez Mazzola, “Campeones del proletariado. El periódico ‘El Obrero' y los comienzos del socialismo en la Argentina" Políticas de la Memoria. CeDInCI, nº 4, 2004

Oddone, Jacinto, Historia del socialismo argentino, Buenos Aires, CEAL, 1983

Poy, Lucas, "Socialismo y anarquismo en la formación de la clase obrera en Argentina: problemas historiográficos y apuntes metodológicos, Archivos de historia del movimiento obrero y la izquierda", 2012, Nº 1, pp. 1-34.

Poy, Lucas, Los orígenes de la clase obrera argentina. Huelgas, sociedades de resistencia y militancia política en Buenos Aires, 1888-1896, Buenos Aires, Imago Mundi, 2015.

Plotkin, Mariano, Freud en las Pampas, Buenos Aires, Sudamericana, 2003.

Rubinich, Luchas, "Van los linyeras... Construcción y circulación de una noción positiva del individualismo romántico vitalista durante la primera mitad del siglo XX argentino", Apuntes de Investigación, nº 13, 2008.

Salais, Robert, N. Baverez y B. Reynaud, L'invention du chômage: Histoire et transformations d'une catégorie en France des années 1890 aux années 1980, Paris, PUF, 1986;

Spalding, Hall, La clase trabajadora (Documentos para su historia, 1890-1912), Buenos Aires, Galerna, 1970

Svampa, Maristella, ¿Civilización o barbarie? El gran dilema de los argentinos, Buenos Aires, Ed. El cielo por asalto, 1994.

Tarcus, Horacio, Marx en la Argentina. Sus primeros lectores obreros, intelectuales y científicos, Buenos Aires, Siglo XXI, 2007

Tarcus, Horacio, “¿Un marxismo sin sujeto? El naturalista Germán Avé-Lallemant y su recepción de Karl Marx en la década de 1890", Políticas de la Memoria, CEDINCI, 2004, pp. 71 a 90

Terán, Oscar (1983), América Latina, positivismo y nación, México, Katún.

Thoburn, Nicholas, "Difference in Marx: the lumpenproletariat and the proletarian unnamable", Economy and Society, Vol. 31, N³, 434-460. 
Topalov, Christian, Naissance du chômeur, 1880-1910, Paris, Albin Michel, 1994

Walters, William Unemployment and government. Genealogies of the social, Cambridge, Cambridge University Press, 2000

Zimmermann, Bénédicte, La constitution du chômage en Allemagne. Entre professions et territoires, Paris, Éditions de la Maison des sciences de l'homme, 2001 